\title{
The effect of pyrolysis temperature on co- pyrolysis of lignite and pistachio seed in a fixed-bed reactor
}

\author{
Özlem Onay \\ Anadolu University, Porsuk Meslek Yuksekokulu, Eskisehir, Turkey \\ e-mail:oonay@anadolu.edu.tr
}

Received: April 28, 2019. Revised: May 7, 2021. Accepted: October 5, 2021. Published: November 15, 2021.

\begin{abstract}
Co-pyrolysis of lignite and pistachio seed (CPLPS) under nitrogen gas was performed in a Heinze retort. The effect of pyrolysis temperature on product distribution of CPLPS investigated under heating rate of $10^{\circ} \mathrm{Cmin}^{-1}$ and blending ratio of $50(w t) \%$. Biomass is higher yield to be pyrolyzed than lignite and addition of biomass promotes the pyrolysis of lignite. In the range of the experimental conditions investigated the yield of the product is proportional to pyrolysis temperature. On the other hand, considerable synergetic effects were observed during the co-pyrolysis in a fixed bed reactor leading to increase in oil yield. Maximum pyrolysis oil yield of $\mathbf{2 7 . 2 \%}$ was obtained at pyrolysis temperature of $550^{\circ} \mathrm{C}$. The obtained oils are characterized by GC, and elemental analysis.
\end{abstract}

Keywords—bio-fuel; co-pyrolysis; lignite; pistachio seed

\section{INTRODUCTION}

Great consumption of fossil fuels and the increasing environmental concern because of air pollutant and $\mathrm{CO}_{2}$ emissions has been promoting an urgent search for new and cleaner energy. The pyrolysis of coal is a promising process for useful liquid fuels and other chemicals, but the yields of these products are limited because of the low $\mathrm{H} / \mathrm{C}$ ratio in coal. Accordingly, it is necessary to supply $\mathrm{H}_{2}$ for coal from other resources. The co-utilization of coal with hydrogen-rich matters such as biomass has more oxygen and hydrogen and less carbon compared to coal, offers a number of advantages. The addition of the renewable biomass can contribute to the reduction of $\mathrm{CO}_{2}$ emissions as the same amount of $\mathrm{CO}_{2}$ is extracted from the atmosphere during the growth period of the plants and reduce emissions of some pollutants, such as $\mathrm{NO}_{\mathrm{x}}$, $\mathrm{SO}_{\mathrm{x}}, \mathrm{PAH}$, and volatile organic compounds [1-4]. Copyrolysis biomass with coal in fixed-bed reactors is a promising alternative that leads to an economical and environmentally friendly use of coals by reducing pollutant emissions as well as to the utilization of biomass residue.

To explain the behavior during the coal/biomass copyrolysis, an understanding of the devolatilisation processes occurring during the initial pyrolysis of both individuals and the blends is necessary. One of the main differences in characteristics of biomass as compared to coal, is that biomass generally releases much higher volatiles, which also contain a large proportion of oxygenated species including water.

Biomass produced a large amount of water at around 220$350{ }^{\circ} \mathrm{C}$ during the pyrolysis process, which can be expected to react with coal particles during the co-pyrolysis. It has also been suggested that biomass present in the coal/biomass blends supplies hydrogen to the subsequent reaction with coal [5].

Recently, interest in the co-pyrolysis of biomass/coal has been growing significantly. A number of studies have carried out pyrolysis of coal/biomass blends to examine the existence of synergistic effects employing various pyrolysis conditions, reactor types and fuel types [6-9].

Turkey has considerable amount of coal reserves of which lignites constitutes major portion with a reserve of 11.8 billion tonnes [10]. Lignites, includes high ash, sulphur, volatile matter and lower heat values vary from 1100 to $4500 \mathrm{kcal} \mathrm{kg}^{-1}$ and therefore it mainly utilized conventionally for power production and heating purposes and cause severe environmental problem.

Lignite exploitation and utilization as a fuel provide large fraction of the needs in Turkish energy system and present the most important atmospheric pollution source. It is, therefore, the objective of this work to study co-pyrolysis of one of Turkish lignite with biomass.

In this study, the effects of various process parameters on the efficiency of the co-pyrolysis process were investigated. The effects of final pyrolysis temperature on the pyrolysis products yield and mixture composition on the chemical compositions of the oil have been investigated.

\section{II.EXPERIMENTAL}

The pistachio seed (Carthamus tinctorius L.) and lignite sample investigated in this study has been taken from vicinity of Batman, located in Southeast Anatolia and KutahyaSeyitömer region, was located in central Anatolia, respectively. Prior to use, the sample was air dried, grounded in a high-speed rotary cutting mill. Particle size range was between $0.5-1.0 \mathrm{~mm}$ for lignite and pistachio seed. Some 
TABLE I

MAIN CHARACTERISTICS OF THE SAFFLOWER SEED AND LIGNITE

\begin{tabular}{lcc} 
Characteristics & Lignite & Pistachio seed \\
\hline $\begin{array}{l}\text { Proximate analysis } \\
\text { (wt.\%,as received) }\end{array}$ & & \\
Moisture & 11.2 & 6.4 \\
Volatile & 32.7 & 82.6 \\
Fixed C & 16.5 & 7.3 \\
Ash & 39.6 & 3.7 \\
& & \\
Elemental analysis & & \\
(wt\%, daf.basis) & 35.6 & 60.4 \\
Carbon & 3.1 & 10.2 \\
Hydrogen & - & 2.8 \\
Nitrogen & 0.6 & - \\
Sulphur & 60.7 & 26.6 \\
Oxygen & & \\
(by difference) & & \\
& 1.05 & 2.03 \\
H/C molar ratio & 1.28 & 0.33 \\
O/C molar ratio & 6.6 & 30.4 \\
Calorific value (MJ/kg) & & \\
\hline
\end{tabular}

characteristics of the used pistachio seed and lignite are given in Table1.

Pistachio seed, lignite and their mixtures were pyrolysed in a Heinze retort and to determine the effect of pyrolysis temperature on the product yields, $10 \mathrm{~g}$ of air-dried sample, was placed in the reactor and the temperature was raised with $10^{\circ} \mathrm{C} \mathrm{min}{ }^{-1}$ to final temperature of either $400,500,550$ or $700^{\circ} \mathrm{C}$ and held for either a minimum of $30 \mathrm{~min}$ or until no further significant release of gas was observed. The flow of gas released was measured using a soap film for the duration of the experiments. The liquid phase was collected in a glass liner located in a cold trap maintained at about $0^{\circ} \mathrm{C}$. The liquid phase consisted of aqueous and oil phases which were separated and weighed. After pyrolysis, the solid char was removed and weighed, and then the gas+water yield was calculated by difference. For these experiments $\% 50$ blending ratio of pistachio seed (weight of pistachio seed in the blend expressed as a percentage of the total sample weight) was used. All the yields were expressed on a dry, ash-free (daf) basis.

The oils analyzed in this study have been obtained in the experimental condition that has given maximum oil yield of CPLPS. Elemental composition $(\mathrm{C}, \mathrm{H}, \mathrm{N}$ and $\mathrm{S}$ ) and higher heating value (HHV) of the sample were determined with an elemental analyzer (LECO TruSpec CHN Elemental Analyzer) and IKA C200 calorimeter.TG analysis was carried out in a LINSEIS Thermowaage L81 thermo gravimetric analyzer coupled with differential thermal analyzer (DTA). The initial weight of the sample was close to $25 \mathrm{mg}$. The samples were heated from room temperature to $800^{\circ} \mathrm{C}$ with a heating rate of $40^{\circ} \mathrm{C} \mathrm{min}^{-1}$ using $\mathrm{N}_{2}$ as the carrier gas at a constant flow rate of $40 \mathrm{mlmin}^{-1}$.
Chemical class compositions of the oils were determined by liquid column chromatographic fractionation. The oil was separated into two fractions as n-pentane soluble and insoluble compounds (asphaltenes) by using n-pentane. The n-pentane soluble material was further separated on activated silica-gel (70-230 mesh). The column was eluted successively with npentane, toluene and methanol to produce aliphatic, aromatic and polar fractions, respectively. Each fraction was dried and weighed. The fractions were analyzed by Fourier transform infrared spectroscopy to determine the efficient separation of the chemical class. In addition, n-pentane fraction was analyzed by GC/MS (HP 6890 GC/MS 30 m i.d; 0.25 mm i.d.; $0.25 \mu \mathrm{m}$ film thickness, HP-5MS column).

\section{III: RESULTS AND DISCUSSION}

The individual curves for each raw material and coal/biomass blends are presented in Fig.1. Percent residual mass decreased with increasing biomass content for blends of coal/biomass. This trend is due to the high volatile content and low fixed carbon content in biomass sample compared to the coal. Biomass and coal are essentially degraded at different ranges of temperature. An important amount of biomass char has been already formed when the major part of coal is decomposing. For pistachio seed, the devolatilization starts at $200^{\circ} \mathrm{C}$ and the weight loss at the final pyrolysis temperature $\left(800^{\circ} \mathrm{C}\right)$ is $80.8 \%$. The coal tested start to devolatilize at higher temperature compared with biomasses. The coal has a peak between $340^{\circ} \mathrm{C}$ and $530^{\circ} \mathrm{C}$. The global weight loss at the final pyrolysis temperature of $800^{\circ} \mathrm{C}$ is $36.2 \%$. Thermogravimetric analysis has been conducted also for the $\% 50$ blending ratio of pistachio seed prepared. The corresponding residual mass curves are reported in Fig.1 as a function of temperature. The curve for blend lies between the curves of the reference materials.

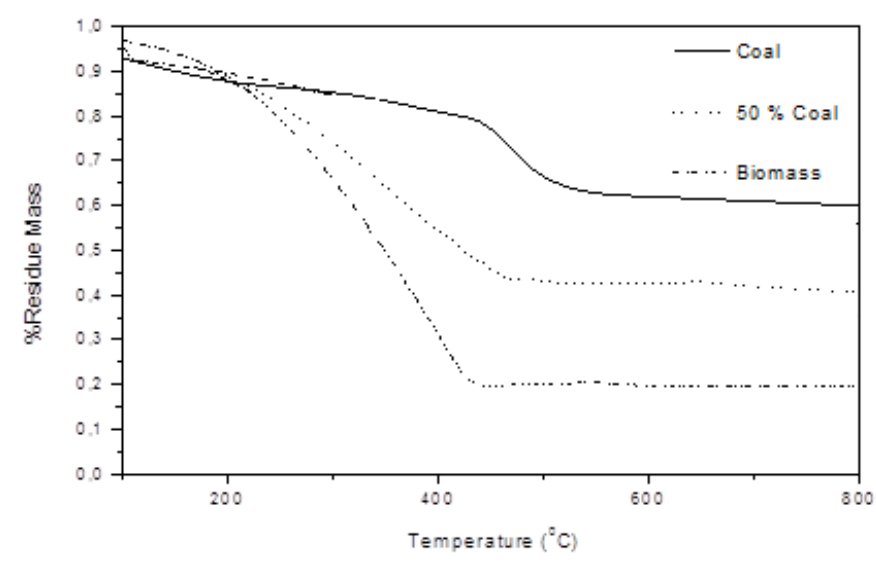

Fig.1. Percent residual mass versus temperature 
The influence of pyrolysis temperature on CPLPS products yield was investigated at $\% 50$ blending ratio of pistachio seed (weight of pistachio seed in the blend expressed as a percentage of the total sample weight). The productions of char, oil and gas yields were plotted against the pyrolysis temperature in Fig.2. The main effect of temperature increase is higher amounts of gas and oil, whilst the yields of char continuously decrease. As shown in Fig.2, the char yield significantly decreased as the final pyrolysis temperature was raised from 400 to $700^{\circ} \mathrm{C}$, in other words, the pyrolysis conversion increased. The decrease in the char yield with increasing temperature could be due to greater decomposition of the samples at higher temperatures. The oil yield increased as the final pyrolysis temperature was raised from 400 to $500^{\circ} \mathrm{C}$, reaching a maximum at a pyrolysis temperature of $550^{\circ} \mathrm{C}$ and decreased at the pyrolysis temperature of $700^{\circ} \mathrm{C}$. In our case, the maximum yield of oil is obtained at pyrolysis temperature of $550^{\circ} \mathrm{C}$. Clearly, the yield of oil is higher, as compared to the expected ones (dashed line, Fig.2.) calculated as the sum of oil fractions produced by pyrolysis of each separated component. At pyrolysis temperature of $550^{\circ} \mathrm{C}$ the CPLPS leads to production of more than $8 \%$ (in mass) of oil for $50 \%$ blending ratio of coal, whatever the origins of studied raw materials.

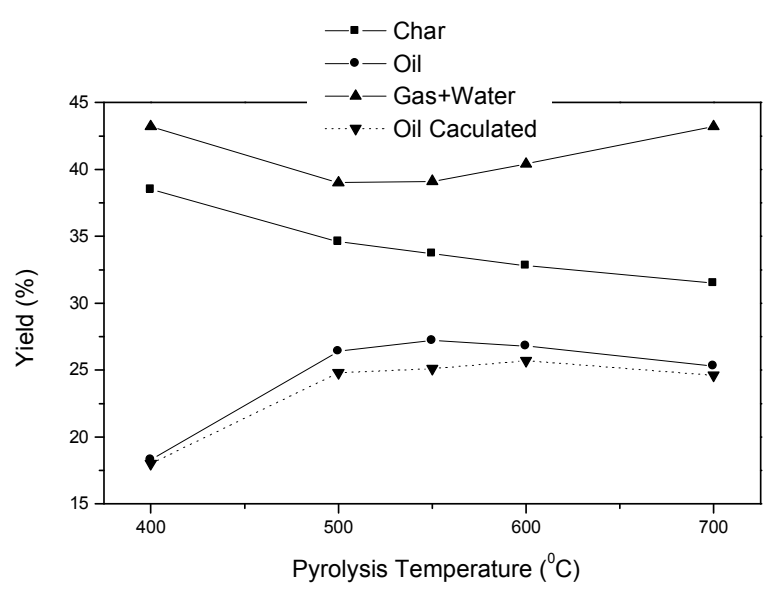

Fig.2. Effects of pyrolysis temperature of CPLPS. The dashed line represents the theoretical additive evolutions of the oils.

The properties of oils are given in Table 2. As it can be seen in Table 1 and 2, oils contain less amounts of oxygen content than that of the original feedstock. The significant decrease in oxygen content of the oil compared to the original feedstock is important, because the high oxygen content is not attractive for the production of transport fuels. Further comparison of $\mathrm{H} / \mathrm{C}$ ratios with conventional fuels indicates that $\mathrm{H} / \mathrm{C}$ ratios of the oils obtained in this study lie between those of light and heavy petroleum products.
TABLE 2.

THE ELEMENTAL COMPOSITIONS AND CALORIFIC VALUES OF PYROLYSIS OILS

\begin{tabular}{lccc}
\hline Component & Coal & Pistachio seed & $50 \%$ coal \\
\hline $\mathrm{C}$ & 79.7 & 70.8 & 76.9 \\
$\mathrm{H}$ & 10.3 & 10.8 & 11.8 \\
$\mathrm{~N}$ & 0.8 & 2.7 & 1.6 \\
$\mathrm{~S}$ & 0.7 & - & 0.5 \\
$\mathrm{O}^{\mathrm{b}}$ & 8.5 & 15.7 & 9.2 \\
$\mathrm{H} / \mathrm{C}$ molar ratio & 1.55 & 1.83 & 1.84 \\
\hline Calorific value $\left(\mathrm{MJkg}^{-1}\right)$ & 40.3 & 36.7 & 41.4 \\
\hline
\end{tabular}

The GC/MS analyses were conducted on the n-pentane fractions to confirm n-alkane and n-alkene hydrocarbons (Fig. 3 ). The n-pentane fractions consist of normal alkanes, alkenes and branched hydrocarbons. The straight chain n-alkanes range from $\mathrm{C}_{6}$ to $\mathrm{C}_{24}$ in the pyrolysis oils.

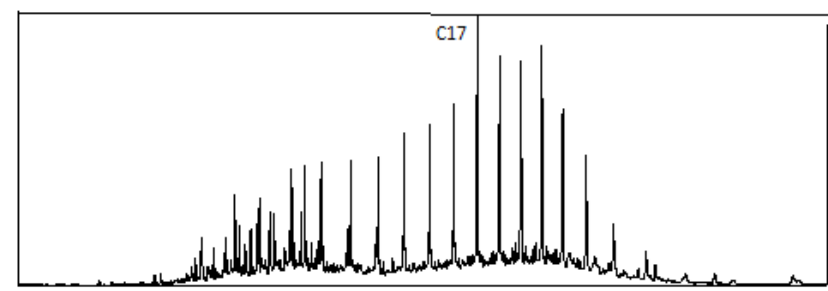

(a)Coal

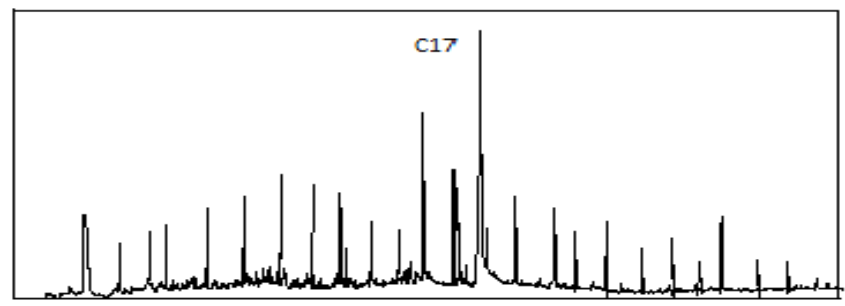

(b)coal/biomass

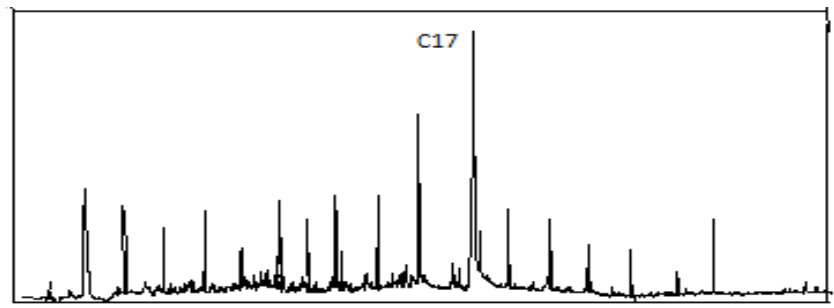

(c) biomass

Fig.3 GC/MS of the n-pentane fraction of pyrolysis oils

\section{IV.CONCLUSION}

In the present work, mixtures of pistachio seed and coal can be radically converted to liquid products by pyrolysis under nitrogen pyrolysis atmosphere in Heinze retort. The results show that the pyrolysis temperature has a great influence on pyrolytic oil. At pyrolysis temperature of $550^{\circ} \mathrm{C}$ the maximum yield of oil is watched. At this temperature, the yield of oil goes to a maximum of about $27.2 \mathrm{wt} . \%$ for $50 \%$ blending ratio 
of coal in the experimental conditions used. The differences between the experimental value and the calculated value confirm that significant synergies can happen during copyrolysis of waste tire and biomass, when pyrolytic vapor are in close contact which are in favor of improving the oil quality.

\section{REFERENCES}

[1]W. Li-gang, Z.Li, X. Shao-ping, "Effects of feedstock on co-pyrolysis of biomass and coal in a free-fall reactor" J. Fuel Chem Technol, 2011, 39(10), pp. 728-734.

[2]L.L.Shang, S.Q. Cheng, H.Q.Zhang,B.Y.Yin, "Investigation of the characteristics of COS released from coal/ biomass blends during copyrolysis" Coal Conversion, 2007, 30(2), pp.18-21.

[3]T. Sonobea, N.Worasuwannaraka, S. Pipatmanomaia, "Synergies in copyrolysis of Thai lignite and corncob" Fuel Processing Technology, 89 , 2008, pp.1371-1378.

[4]L. Zhang, S.P. Xu, W. Zhao, S.Q. Liu, "Co-pyrolysis of biomass and coal in a free fall reactor" Fuel, 2007, 86 (3): pp.353-359.

[5]A.H. Stiller, D.B. Dadyburjor, J. Wann, D. Tian, J.W. Zondlo, "Coprocessing of agricultural with coal and biomass waste" Fuel Process. Technol. 49, 1996, pp.167-175.

[6]L.L. Shang, S.Q. Cheng, H.Q. Zhang. "Experimental study on pyrolysis behaviors of coal and biomass blending". Acta Energiae Solaris Sinica, 28(8), 2006, pp. 852-856.

[7]O. Onay, E. Bayram, O.M. Kockar, “ Copyrolysis of seyitomer-lignite and safflower seed: influence of the blending

ratio and pyrolysis temperature on product yields and oil

characterization" Energy Fuels, 2007, 21(5), pp.3049-3056.

[8]H.X.Wu, H.B. Li, Z.L. Zhao, "Thermogravimetric analysis and pyrolytic kinetic study on coal/ biomass blends". Journal of Fuel Chemistry and Technology, 2009, 37(5), pp. 538-545.

[9]D.K.Park, S.D. Kim, S.H.Lee, J.G. Lee, "Co-pyrolysis

characteristics of sawdust and coal blend in TGA and a fixed bed reactor". Bioresour Technol, 2010, 101 (15), pp. 6151-6156.

[10]ETKB/EIGM, 2011, Updating the Study of Coal Reserves Report, September 2011.

\section{Creative Commons Attribution License 4.0 (Attribution 4.0 International, CC BY 4.0)}

This article is published under the terms of the Creative Commons Attribution License 4.0 https://creativecommons.org/licenses/by/4.0/deed.en_US 